\title{
Using brainstorming through social media to promote engineering students' teamwork skills
}

\author{
Natawee Chaijum* \\ * Program of Electromechanic Manufacturing Engineering, Faculty of Engineering and Industrial Technology, \\ Bansomdejchaopraya Rajabhat University, Bangkok, Thailand \\ For correspondence: natawee.ch@bsru.ac.th
}

\begin{abstract}
:
Engineering students have placed demands on how their develop competency in teamwork skills, which is one of the most important competences for most engineers. Due to the advanced information technology, learning from computer-supported collaborative technologies could be more effective for learning nowadays. Brainstorming method is a form of learning in groups, combining with social media technology that can support learning to be more effective, especially for teamwork skills. In this research, we studied the engineering students' teamwork skills and the satisfaction of our learning method. We evaluated the teamwork skills in 2 ways, by the teamwork process and by the group assignment results. The findings indicate that the use of our learning method may offer an interesting way to improve engineering students' teamwork skills and feedback from students found that they are satisfied with their teamwork skill practice.
\end{abstract}

Keywords: brainstorming, engineering students, learning method, social media, teamwork skills, undergraduate students

\section{Introduction}

Technological progress in Thailand is currently developing rapidly and continuously in many parts such as economy, society, politics, government, industry and innovation, which are all connected. Technology have had a role in people of all genders and ages, for example, in education, teachers must apply technology to teach students to learn and gain knowledge to be used in the workplace or students have to study more information from various sources on the internet in order to use in studied or for future careers etc. (Division of Research Administration and Education Quality Assurance, 2017; Wittayasin, 2017). During this twenty-first century, the skills that are necessary in this century can be divided into 4 topics (4Cs) which are critical thinking, communication, collaboration and creativity. It also found that mathematical and science learning in the country was considered as a weakness; therefore, it is necessary to reform education in order to develop knowledge for students who are graduating in order to have knowledge and skills that meet the needs in this twenty-first century (Joynes, Rossignoli and Fenyiwa, 2019).

Learning management in the twenty-first century depends on many factors such as lecturer, student and executive etc. (Thipkrongtham, Prapa and Reangsri, 2017), which the current learning management is very different from the past learning. In the past, most of the lecturers are people who transfer knowledge to students or get knowledge from reading books, but nowadays, they get knowledge from a lot of information. Nowadays, learning has changed, the students have to study and search for information from various sources, especially from the internet by using various search tools such as smart phones, notebook computers, tablets, PCs, etc. while the lecturer will change their duties to coach in order to suggest when students do not understand and add knowledge that the 
students still lack. Moreover, students must be socio-technical, which combines social behaviour with technological knowledge to create maximize efficiency in work or study (Trevelyan, 2019).

Brainstorming is a type of learning management method in groups of 4 to 9 people to express students' opinions about information, in terms of concept mapping and words in order to find answers, solve problems, set objectives, analyse data, and summarize from the given topics which all of this could make students develop their thinking systematically to the skills needed in the twentyfirst century (Sottipolanun, 2017). Brainstorming method is divided into 3 method; Traditional brainstorming (TBS), Nominal brainstorming (NBS) and Electronic Brainstorming (EBS), which the effective brainstorming techniques are NBS and EBS, the advantage of EBS is the method that allow students to express their opinions freely (Al-Samarraie and Hurmuzan, 2018).

Social media is relatively new as it deals with different online communication platforms, a form of digital communication via the internet to make people communicate between each other or in groups which social media can be divided into following categories: social networking sites, micro-blogs, videos and photo sharing websites, personal and corporate blogs, forums, discussion boards, and group geo-spatial taggings and online multiplayer gaming platforms (Wannaphapha, 2017). The use of social media in higher education are many online social networks (OSNs), especially Facebook, which students use for learning, researching and communicating. With the use of OSNs as a tool can cause benefits in higher education learning. (Zachos, Paraskevopoulou-Kollia and Anagnostopoulos, 2018). For the survey of internet usage in Thailand 2018, Thai people use the internet averagely 10 hours and 5 minutes per day, increasing from 3 hours 30 minutes from 2017. The most internet usage activity is social media usage (Electronic Transactions Development Agency, 2019) and in 2019, the proportion of internet usage has been divided from various devices, it is found that the internet usage via smartphone has the first ranking, followed by notebooks, computers, tablet PCs and other devices, respectively. However, a number of empirical studies (Bleakley et al., 2014; Ndaku, 2013) show that most students in high schools frequently use social media to connect to friends in chat rooms, watch movies and music videos, and play online games.

As mentioned above, undergraduate students, who study in the engineering field, teamwork skills is one of the most important competences for most engineers and for a better understanding of the theory-practice relationship in technology-driven in twenty-first century. In this research we use brainstorming learning method with social media to promote teamwork skills for undergraduate engineering students which will help them to think, analyse data and solve problems. Also, they use social media as a tool to search for information, communicate between group members and the lecturers in order to deliver the teamwork skills.

\section{Method}

In this research, the purpose of this paper are to study the students' teamwork skills and the students' satisfaction of the learning method. We choose a special topic in electrical engineering subject with undergraduate students at Department of Electromechanic Manufacturing Engineering. LINE and Facebook, which are applications that can be used easily and conveniently, and can also send information in many formats such as texts, images, videos, or document files, which are used in social media. Our research method is divided into 3 steps, first is the introduction step, which the lecturer will explain our learning method by using created learning management plan consisting of course descriptions, learning objectives, learning methods, assessment criteria, and other important details. Movingto the learning step, which the lecturer will describe the content on the specified topic and the topic will be given to the students to assess their teamwork skills by the following topics in each week, which are PM 2.5 dust, artificial intelligence system, Internet of things (IoT), smart home, smart city and $5 \mathrm{G}$ technology, respectively. 
Each week, the lecturer will divide the students into 5 groups with 4 members, in which the students set their roles and responsibilities of each group member and brainstorm to complete their group assignment, and also hand out the worksheet and evaluation criteria to all students. After that, each group select possible and appropriate issues for the given topics, then jointly discuss the selected issue with consideration, andsummarize the issues or methods and present their assignment results in front of the class, then the lecturer evaluates the students' teamwork skills at the end of week. Finally, the conclusion step, which is the end of the learning activity. Both students and lecturer will summarize the problems or found obstacle from the learning method and summarize additional issues. At the end of the course, the students must complete the satisfaction assessment forms. Teamwork skills assessment is divided into 2 parts, the first part is to assess the teamwork process as shown in table 1, and the second part is to assess the group assignment scores. Finally we collect feedback from the students' satisfaction of our learning method.

Table 1. Teamwork skill process criteria

\begin{tabular}{ll}
\hline \multicolumn{1}{c}{ Criteria } & \multicolumn{1}{c}{ Details } \\
\hline Interaction & $\begin{array}{l}\text { working together with others that have the characteristics of } \\
\text { understanding each other, helping each other, supporting, also } \\
\text { having a good relationship to create a good working environment }\end{array}$ \\
\hline Communication & $\begin{array}{l}\text { having straightforward communication and allows the } \\
\text { opportunity to respond or ask questions without conflicts with } \\
\text { each other }\end{array}$ \\
\hline Participation and & $\begin{array}{l}\text { involved in working as a team in work since the beginning with } \\
\text { responsibility }\end{array}$ \\
\hline Hallaboration & $\begin{array}{l}\text { working together in which all the team members provide a clear } \\
\text { understanding of the purpose of the work }\end{array}$ \\
\hline Trustworthiness & $\begin{array}{l}\text { loving, kindness, liking, and confidence that lead to trust until } \\
\text { trust in that person willingly }\end{array}$ \\
\hline Respecting each other & $\begin{array}{l}\text { listening to one another, respect for the role of each other, accept } \\
\text { differences and ready to work together willingly }\end{array}$ \\
\hline
\end{tabular}

\section{Results}

Our findings is divided into 2 parts, the teamwork process and the group assignment score, and students' satisfaction of our learning method.

Firstly, our teamwork skill process was evaluated from 6 assignments, which we divided into 6 criteria. It is explored that the students had the ability in the process of working as a team, 2 groups are at a good level and 3 groups are at moderate level. In figure 1, it shows the average scores of the student group teamwork skill process. The students in the group have a good understanding of teamwork which can be seen from having the same goal and trying to help each other to achieve the goal but they missed some interaction between each other in some period of doing their assignments causing from their deep focus with social media, so, the lecturer must tell the students to always be alert to have interaction as well. 


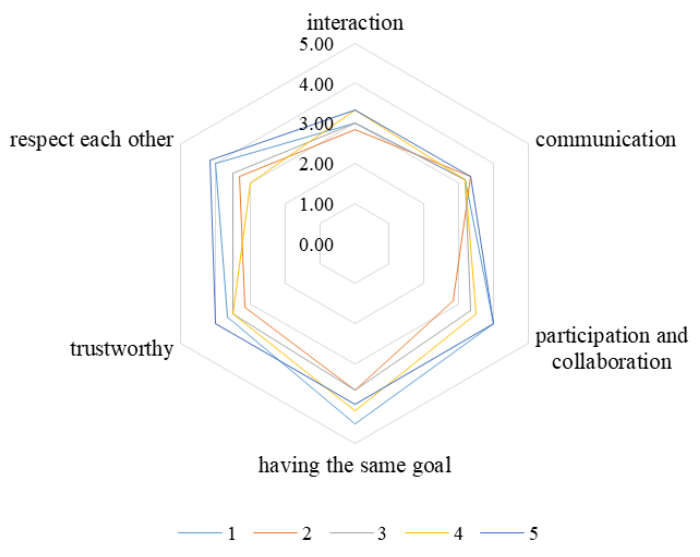

Figure 1. The average score of students' teamwork skill process criteria

Secondly, we evaluate the group assignment score, which we divided the assessment criteria into 7 topics, students will be able to 1) write the main topic at the header of paper, 2) use time less than 1 hour, 3) use images or symbols for writing conceptual diagrams, 4) specify the key points, 5) explain the details of the key points, 6) analyse the details of the key points, and 7) use social media to exchange information. It is explored that students have the ability to work as a team at a very good level for 1 group, good level for 2 groups and moderate level for 2 groups. In figure 2 shows the average scores from the assignments; the assignments of each group is correct and completed according to assessment criteria, which the topic is about the technology that is currently happening and also a topic that student is studying in order to be used in their engineering's projects. Moreover, all groups can follow the criteria about how to write the diagrams and use the social media, but most of the groups miss some details of the key points and not be able to analyse the details of the key points clearly causing from their lack of analysing and concluding with other members and they spent too much time on searching the information.

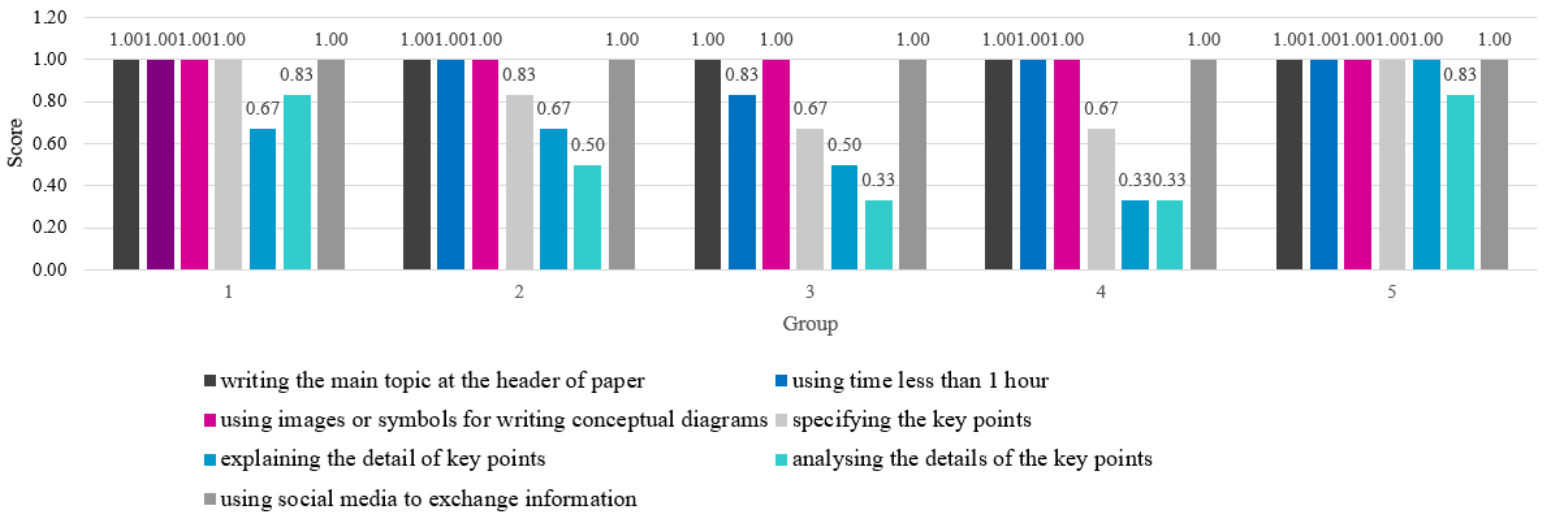

Figure 2. Students' teamwork assignment average score in each group

The example of students' assignment, as shown in figure 3, can be seen that students can follow the specified criteria with the work as a team. The results show that they can connect the relationship between the information well and feel free to design or draw even in some assignments they missed some details but have been improved in the next assignment. 


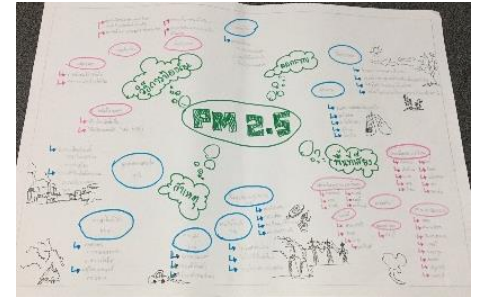

(a)

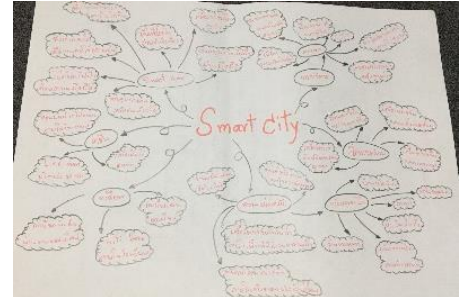

(b)

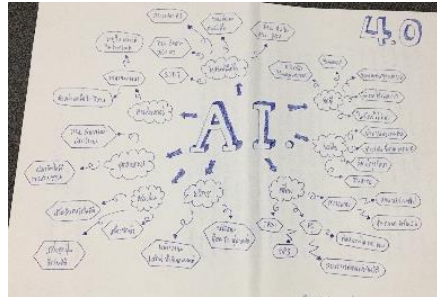

(c)

Figure 3. Example of students' group assignment (a) PM 2.5, (b) Smart city and (c) AI

Finally, we evaluate the students' satisfaction of our leaning method, it is explored that the average satisfaction are at a high level with the topic of learning method, enabling our engineering students to search for information from social media by themselves, as the students are familiar with the use of these types of technology and they have learned how to work as a team. Also, the students prefer to this learning method, but this learning method still encounters the problem; the information that they found is not correct as it should be. The students must have critical thinking skills and accept the opinions of others more. The evaluation result can be seen in table 2 .

Table 2. The evaluation of our learning method from students' satisfaction

\begin{tabular}{|c|c|c|}
\hline Statement & Score (SD) & Quality level \\
\hline \multicolumn{3}{|l|}{ Learning management plan } \\
\hline 1. Help me to understand the subject more & $3.30(0.57)$ & Moderate \\
\hline 2. I can search for information on social media by myself & $4.65(0.49)$ & Excellent \\
\hline 3. Train me to have human relations with my team members & $4.05(0.83)$ & Good \\
\hline 4. I have learned how to work as a team & $3.90(0.79)$ & Good \\
\hline 5. I feel that I can accept the others' opinions & $3.45(0.69)$ & Moderate \\
\hline \multirow{2}{*}{ 6. I can use this skills in everyday life } & $4.10(0.72)$ & Good \\
\hline & $3.91(0.68)$ & Good \\
\hline \multicolumn{3}{|l|}{ Learning content } \\
\hline 7. The content is in accordance with the learning objectives & $4.00(0.86)$ & Good \\
\hline 8. The content is appropriate for me & $3.90(0.55)$ & Good \\
\hline 9. The content is linked continuously & $4.00(0.73)$ & Good \\
\hline 10. The content can be applied to my senior's project & $4.05(0.89)$ & Good \\
\hline 11. The content is appropriate for the ability or aptitude for me & $3.80(0.70)$ & Good \\
\hline 12. The course content is suitable for current technology & $4.30(0.47)$ & Good \\
\hline 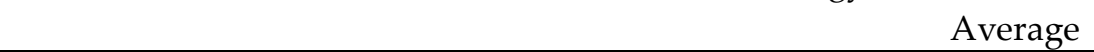 & $4.01(0.70)$ & Good \\
\hline
\end{tabular}

Learning activities

13. I received the suggestion for the use of social media from the

$4.30(0.57) \quad$ Good lecturer

14. The content is appropriate for learning activities

$4.15(0.75) \quad$ Good

15. I can think assertive

$4.35(0.49) \quad$ Excellent

16. I have better thinking process

$4.20(0.52) \quad$ Good

17. I have better problem-solving skills

$3.65(0.67) \quad$ Good

18. I feel that the learning time is appropriate for me

$4.10(0.45) \quad$ Good

19. The activities are suitable for increasing the teamwork skills

$4.15(0.59) \quad$ Good

Average $4.13(0.58) \quad$ Good

Group assessment

20. The assessment is appropriate for the subjects

$4.35(0.49) \quad$ Good

21. The assessment has clear criteria and easy to understand

$4.20(0.62) \quad$ Good

22. The assessment covers all the subject content

$3.95(0.69) \quad$ Good




\begin{tabular}{cccc}
\hline Statement & & Score (SD) & Quality level \\
\hline & Total average & $\mathbf{4 . 0 4 ( 0 . 5 8 )}$ & Good \\
\hline
\end{tabular}

\section{Conclusion and discussion}

In conclusion, using social media in learning can make engineering students have collaboration, communication, interaction, information dissemination, resource sharing, and socialization to promote engineering students' teamwork skills, which can stimulate the students' learning that makes it easier for students to communicate and understand by using informal languages for conversation and make students feel more relaxed (Mauluddiyah et al., 2018). Moreover, after learning, most students have developed their systematic thinking skills and can apply organized information to be easier understood as can be seen from the assignment. In conclusion, our learning method can disseminate knowledge, encourage students' analytical, synthesis and creative thinking skills in systematic and effective way and the most important is that they can work as a team. As for the lecturer, from the learning method, the use of teamwork teaching can help the lecturer manage the teaching time and develop the knowledge and abilities of the teachers (Vesikivi et al., 2019). Also, students are satisfied in the learning method, which can help them become more motivated, confident, and engaged, as can be seen in the positive behaviour of the students in teamwork (Goswami et al., 2017; Unina and Bearing, 2016).

\section{Suggestions}

Our suggestions from this research are the lecturer should teach their students about reliable screening from social media, study from various references and compare them to get the most accurate and convincing information, and our recommendation for the next research is to find out the learning method that can develop all criteria in digital sculpting skills or find other interesting learning method to be implemented with technology.

\section{Acknowledgements}

Author would like to express sincere thanks to Research and Development Institute Bansomdejchaopraya Rajabhat University and Faculty of Engineering and Industrial Technology, Bansomdejchaopraya Rajabhat University, Bangkok, Thailand.

\section{References}

Al-Samarraie, H. and Hurmuzan, S., (2018). A review of brainstorming techniques in higher Education Thinking Skills andCreativity, 27, 78-91.

Bleakley, A., Vaala, S., Jordan, A. B., and Romer, D., (2014). The Annenberg media environment survey: Media access and usein U.S. homes with children and adolescents. In A. B. Jordan, D. Romer, A. B. Jordan, \& D. Romer (Eds.) Media and the Well-being of Children and Adolescents. Oxford University.

Division of Research Administration and Education Quality Assurance, (2017) "Thailand 4.0 Model for Driving Thailand toWealth, Stability and Sustainability." http://www.libarts.up.ac.th/v2/img/Thailand-4.0.pdf, (accessed January 2020)

Electronic Transactions Development Agency, (2019) "Thailand Internet User Behavior 2019"https://www.etda.or.th/publishing-detail/thailand-internet-user-behavior-2019-en.html (accessed January 2020)

Goswami, B., Jain, A. and Koner, B. C., (2017). Evaluation of Brainstorming Session as a Teaching-learning Tool amongPostgraduate Medical Biochemistry Students. International Journal of Applied and Basic Medical Research, 7(1), 1518.

Joynes, C., Rossignoli, S., and Fenyiwa A., E., (2019). 21st Century Skills: Evidence of issues in definition, demand and deliveryfor development contexts (K4D Helpdesk Report). Brighton, UK: Institute of Development Studies.

Mauluddiyah, A., Annisa, DI., Sari, DFW, Ratmaningsih N., and Nugraha E., (2018). Idea Generation on Social Media BasedBrainstorming Session. Proceedings of the Mathematics, Informatics, Science, and Education International Conference (MISEIC 2018).

Ndaku, A. J., (2013). Impact of social media on the students' academic performance in Ghana. Networking, 18(5), $275-285$. 
Sottipolanun, S., (2017). Developing the System Thinking Capability by using Brainstorming to Create Concept Mapping inthe First-year Students of Bachelor of Education, College of Teacher Education. Phranakhon Rajabhat University TechnicalEducation Journal King Mongkut's University of Technology North Bangkok, 8(1): 170-177.

Thipkrongtham, O., Prapa T., and Reangsri S., (2017). Factors Affecting Learning Organization in the 21st Century forBenjaburapha Subarea Teachers Under the Jurisdiction of the Secondary Educational Service Area Office Two. Narkbhut Paritat journal Nakhon Si Thammarat Rajabhat University, 9(1), 97-108.

Trevelyan, J., (2019). Transitioning to engineering practice. European Journal of Engineering Education, 44(6): 821-837. Unin, N. and Bearing, P., (2016). Brainstorming as a Way to Approach Student-Centered Learning in the ESL Classroom.Procedia - Social and Behavioral Sciences, 605 - 612.

Vesikivi, P., Lakkala, M., Holvikivi, J., and Muukkonen, H., (2019). Team teaching implementation in engineering education: teacher perceptions and experiences. European Journal of Engineering Education, 44(4), 519-534.

Wannaphapha, T., (2017). Social Media with Education. Journal of Education Mahasarakham University, 11(1), 7-20.

Wittayasin, S., (2017). Education Challenges to Thailand 4.0. International Journal of Integrated Education and Development, 2 (2),2935 .

Zachos, G., Paraskevopoulou-Kollia, E. A., \& Anagnostopoulos, I., (2018). Social Media Use in Higher Education: A Review.Education in Science, 8(4), 194. 